\title{
Overview of the Brazilian Computer Society's Council for Human-Computer Interaction (CEIHC)
}

\author{
Cristiano Maciel $^{1}$, Elizabeth Furtado ${ }^{2}$, Marco Winckler ${ }^{3}$, \\ Milene Silveira ${ }^{4}$, and Raquel Prates ${ }^{5}$ \\ ${ }^{1}$ Universidade Federal de Mato Grosso (UFMT) \\ ${ }^{2}$ Universidade de Fortaleza (UNIFOR) \\ ${ }^{4}$ Université Paul Sabatier (UPS) \\ ${ }^{3}$ Pontifícia Universidade Católica do Rio Grande do Sul (PUC-RS) \\ ${ }^{5}$ Universidade Federal de Minas Gerais (UFMG)
}

\begin{abstract}
CEIHC is an acronym that stands for Council for Human-Computer Interaction. This council is composed by members of the Brazilian Computer Society (SBC) and its main goal is to promote the field of Human-Computer Interaction in Brazil. In this paper, we detail the missions assigned to the CEIHC and its recent activities. Moreover, challenges for the development of this field and future activities are discussed in this paper.
\end{abstract}

Keywords: Human-Computer Interaction, HCI research, HCI education.

\section{Introduction}

The Brazilian Computer Society ${ }^{1}$ (SBC) is a scientific organization whose main goal is to promote the technical development of computing at its various disciplines that are represented by a dedicated council. The CEIHC ${ }^{2}$ is the SBC's council for all issues related the field of Human-Computer Interaction (HCI). This council is usually composed of 5 members: past and future chairs of the Brazilian Symposium in HCI and one regional position who is elected by the Brazilian HCI community in an assembly organized during that symposium. HCI symposium had its first edition in 1998, and is the main forum for HCI publication and discussion in Brazil since then.

Initially CEIHC was created to assure a good communication channel between the HCI community and SBC, as well as act as steering committee of the HCI symposium. Although supporting the event organization continues to be its main task, due to the growth of the community CEIHC has expanded its focus to support the HCI community in Brazil in other relevant issues, namely: HCI education, HCI research and dissemination of HCI field in Brazil. We next briefly present the CEIHC's effort in each direction and what we see as challenges for the near future.

\footnotetext{
${ }^{1}$ Sociedade Brasileira de Computação, http : / /www . sbc . org . br /

${ }^{2}$ Comissão Especial de Interação Humano-Computador,

http: //comissoes.sbc.org.br/ce-ihc/
} 


\section{CEIHC's Attributions and Activities}

The CEIHC, on behalf of the SBC, is responsible for the financial and technical aspects of the Brazilian HCI symposium. Beside this symposium, that in its last edition (2010) had approximately 180 participants, in 2002 CEIHC started supporting the Latin-American Conference on HCI (CLIHC).

Another CEIHC's activity is to develop strategies for promoting HCI education in computer science programs. The community has been invited to discuss this theme at the symposium (a working group in 2006 [2], a panel in 2008 [1] and a workshop in 2010).

Besides that CEIHC is associated with scientific organizations such as IFIP and ACM. CEIHC is responsible for indicating to SBC the Brazilian representative at the IFIP TC 13, and also the BR-CHI (ACM/SIGCHI Local Chapter in Brazil) has its annual meeting during the $\mathrm{HCI}$ symposium.

In Brazil there are defined criteria for evaluating research, based on the evaluation of conferences and journals in the field and it has a direct impact on researchers' evaluation and support to their research. Thus, one of the main topics of CEIHC is analyze the criteria established for the HCI field.

Dissemination of HCI in Brazil, another attribution of CEIHC, is done mainly through CEIHC's website ${ }^{2}$ and an HCI discussion list (ihc-1@sbc.org.br) managed by CEIHC. Also, in 2009 a special issue on HCI was organized for SBC's bulletin.

\section{Achievements and Future Challenges}

Among the achievements of CEIHC are the dissemination of the success cases of regular organization of $\mathrm{HCI}$ events in Brazil; the promotion of the relationship of the Brazilian community with international associations such as IFIP and ACM/SIGCHI; and, the development of actions and projects according to the SBC Challenges 20062016, specially concerning to "Citizens' universal access to knowledge" [3]. The challenges to the future include: continuing to develop strategies for promoting $\mathrm{HCI}$ education in computer science programs; make national conferences attractive for research, in order to bring visibility of national research outside; find ways to promote the integration of researchers and practionners of $\mathrm{HCI}$ related fields in order to discuss their theories and practices and to apply them for the sustainable development of Brazil; and, promote the dissemination, development and use of HCI.

\section{References}

1. de Souza, C.S., Baranauskas, M.C., Prates, R.O., Pimenta, M.S.: HCI in Brazil: lessons learned and new perspectives. In: VIII Brazilian Symposium on Human Factors in Computing Systems, Porto Alegre, pp. 358-359 (2008)

2. Silveira, M.S., Prates, R.O.: Uma Proposta da Comunidade para o Ensino de IHC no Brasil. In: XV Workshop sobre Educação em Computação, Rio de Janeiro, pp. 76-84 (2007)

3. SBC. Grand Challenges in Computer Science. Porto Alegre (2006) 